\title{
GÊNERO E ENVELHECIMENTO: UMA ANÁLLSE SOBRE O CORPO ENVELHECIDO A PARTIR DAS REPRESENTAÇÕES SOCIAIS COMPARTILHADAS POR HOMENS E MULHERES VELHOS/AS
}

\author{
GENDER AND AGING: AN ANALYSIS OF THE AGED BODY FROM THE SOCIAL REPRESENTATIONS SHARED \\ BY OLD MEN AND WOMEN
}

\section{RESUMO}

Este artigo propõe analisar as representações sociais de homens e mulheres sobre seus corpos envelhecidos. Existem duas noções atreladas ao imaginário social do envelhecimento: a primeira consiste na representação tradicional da velhice atribuindo ao/a velho/a uma imagem associada à decadência física e a ausência de papeis sociais; e outra noção confere novos significados a esta etapa da vida, incentivando a autovigilância dos corpos e a responsabilização dos sujeitos pelo sucesso do envelhecimento. Neste sentido, a pesquisa apresentada visa compreender as representações dos/as velhos/as sobre o processo de envelhecimento a partir do gênero. A metodologia do estudo consistiu em entrevistas semiestruturadas em uma Instituição de Longa Permanência para Idosos (ILPIs) e um grupo de convivência, ambos localizados em Cuiabá (MT). Constatou-se que as representações sociais compartilhadas enaltecem o corpo jovem como padrão hegemônico de corpo que produz trabalho. Ademais, a construção social do gênero revela-se como aspecto fundamental na experiência do envelhecimento, especialmente para as mulheres, pois sobre estas incide uma expressiva cobrança social para a manutenção da juventude de seus corpos.

Palavras-chave: Envelhecimento. Gênero. Corpo. Representações Sociais.

\begin{abstract}
This article proposes to analyze the social representations of men and women regarding their aging bodies. There are two notions linked to the social imaginary of aging: the first consists in of the traditional representation of old age, assigning to the old person an image associated with physical decay and the absence of social roles; the other notion gives new meanings to this stage of life, encouraging awareness of their bodies and accountability of the subjects for successful aging. In this regard, the presented research aims to understand the representations of the elderly about the aging process from gender. The methodology of the study consisted
\end{abstract}

\section{Stephanie Natalie Burille}

Mestre em Sociologia pela Universidade de Brasília (UnB). E-mail: snb.stephanie@gmail.com Silvana Maria Bitencourt

Doutora em Sociologia Política pela UFSC. Professora Associada I do Departamento de Sociologia e Ciência Política e do Programa de Pós-Graduação em Sociologia da UFMT. E-mail: silvanasocipufmt@ gmail.com 
of semi-structured interviews in a Long-term Care Institution and a companionship group, both located in Cuiabá (MT). It was found that shared social representations enhance the young body as a hegemonic pattern of the body that produces work. Furthermore, the social construction of gender is revealed as a fundamental aspect in the experience of aging, especially for women, since they are expressively demanded by society to maintaining the youth of their bodies.

Keywords: Aging. Gender. Body. Social Representations.

\section{Introdução}

Este artigo tem como objetivo analisar as representações sociais compartilhadas por homens e mulheres idosos/as de Cuiabá (MT) sobre o corpo envelhecido. $\mathrm{O}$ envelhecimento é um processo que ocorre visivelmente no corpo, podendo afetar os sentimentos e as emoções dos sujeitos. Contudo, o processo de construção da identidade de gênero no Ocidente tem ocorrido de modo distinto para homens e mulheres, se considerarmos o processo da divisão sexual do trabalho, que propõe uma dicotomia para identificar o que é ser homem e ser mulher socialmente. As mulheres tiveram historicamente seus corpos destinados a maternidade e ao trabalho de cuidado, este desenvolvido na esfera privada, ao passo que os homens estariam destinados ao mundo público, ou seja, ao mundo do trabalho. Estas dicotomias constituíram-se a partir de hierarquias, portanto, assimetrias que se cristalizaram ao longo da história identificando homens com trabalho/produção e mulheres com maternidade/reprodução. A menopausa tem sido reconhecida como a porta de entrada para o envelhecimento do corpo das mulheres, pois é nesta fase que a mulher "perde" os atributos de feminilidade socialmente valorizados como: beleza, juventude e fertilidade (FERNANDES; GARCIA, 2010; MARTIN, 2006; GUERRA, 2017).

Nesse sentido, mulheres tendem a ser mais cobradas socialmente quando apresentam sinais de envelhecimento ganhados a partir da idade, como: cabelos brancos, ganho de peso, rugas e linhas de expressão aparentes, ao contrário dos homens que pouco se comenta sobre andropausa e problemas como a ereção surgidos com a idade.

Assim, a Sociologia do corpo propõe analisar os princípios que foram postulados pelas Ciências Naturais, pautados na representação biológica do corpo enquanto um conjunto de órgãos, tecidos e estruturas fisiológicas. Para além das formulações da biologia, o corpo é uma estrutura simbólica, socialmente construído, produz significados no interior de uma determinada cultura (LE BRETON, 2007). Desse modo, o pensamento sociológico e suas metodologias de análise sistemática e abordagens pautadas na compreensão das significações da realidade social, fornece meios para desvendar os imaginários, lógicas sociais e sentidos implícitos e imbricados na corporeidade. A articulação entre a perspectiva teórica das representações sociais, 
a Sociologia do corpo e os estudos de gênero, propõe acrescentar novos elementos nas ponderações que cercam o fenômeno do envelhecimento.

Simone de Beauvoir (1990) retrata a realidade dos/as velhos/as franceses/as da década de 1970 e descreve o padrão das alterações fisiológicas do corpo vivenciado por homens e mulheres sob efeito do processo de envelhecimento. Baseada nas constatações biomédicas, a autora menciona as mudanças na aparência física que implicam em despigmentação capilar, desidratação e a perda de elasticidade da pele, perda dos dentes e dos cabelos, engrossamento das pálpebras, atrofiamento dos órgãos, esclerose das articulações, entre outros.

Algumas mudanças fisiológicas afetam o sistema reprodutor dos corpos, alterando os níveis hormonais e atrofiando os órgãos sexuais. A interrupção da função reprodutora das mulheres ocorre por volta dos 50 anos, quando o ciclo ovariano e da menstruação sofrem o impedimento da fecundação. Os homens observam a redução ou impotência das capacidades de ereção e ejaculação, o que não significa a total extinção da libido. Essas alterações corporais são inerentes ao processo de envelhecimento. Homens e mulheres tendem a desencadear todas ou a maioria destas mudanças.

As diferenças sexuais localizadas no corpo, bem como as mudanças provenientes dos aspectos naturais foram apropriadas pelo saber científico, consagrado como autoridade epistêmica legítima para falar do corpo. Os pressupostos e conteúdos comungados como conhecimento produzido pelas ciências biológicas atribuem a produção das interpretações dos processos, diferenças sexuais e corporais como puramente fisiológicas. No entanto, Citeli (2001, p. 132) argumenta que estas explicações supostamente oriundas da natureza e do corpo biológico não estão desvinculadas dos arranjos sociais vigentes em cada época. Estas explicações servem para fundamentar variações nas habilidades, capacidades, padrões cognitivos, comportamentos e sexualidades.

O uso da linguagem científica e as interpretações sobre os processos biológicos não estão isentos de ideologias, dogmatismos, juízos de valor que atravessam as subjetividades dos sujeitos produtores de conhecimento (JAPIASSU, 1981). A "verdade" científica compartilhada pela ciência sobre as diferenças entre os sexos, usa de metáforas ou uma forma de linguagem determinista para descrever características dos órgãos sexuais, o funcionamento e as relações entre estes órgãos. Martin (1996) evidencia as representações sociais da relação entre o óvulo - o "sujeito passivo" - e o espermatozoide - "o sujeito ativo" - baseadas na naturalização de estereótipos culturais. Uma linguagem semelhante figura a abordagem sobre a menopausa e opera como difusor dos contrastes entre os órgãos. Se para as mulheres ocorre a "degeneração" das células reprodutivas, os homens "produzem" espermatozoides.

As noções que favorecem o corpo masculino como modelo hegemônico de corpo humano se sustentam nos preceitos da Medicina Clássica Ocidental que conservam as virtudes masculinas da força, virilidade e vigor do corpo e da alma, como referência de saúde e juventude. As corporeidades que concernem ao feminino, 
ao velho, à criança e à doença foram em grande medida marginalizadas na história das sociedades ocidentais (FOUCAULT, 2005).

As mudanças corporais são relevantes na problematização dos aspectos socioculturais no processo de envelhecimento nas sociedades ocidentais. A forma como o corpo velho está inserido socialmente desvela a sua suscetibilidade às intervenções científicas e tecnológicas, às leis, aos códigos morais e às representações criadas a respeito destes corpos, além dos discursos sobre eles reproduzidos (GOELLNER, 2012).

O envelhecimento é vivenciado por cada sujeito em sua história particular, portanto, necessita ser analisado por meio de marcadores sociais como: classe, raça, gênero e gerações. Brito da Motta (2013) convida a considerar os diferentes "envelhecimentos", no sentindo de destacar seu caráter plural e heterogêneo. Para a autora, a velhice é um fenômeno biossocial que não atém singularidade, portanto:

Claramente existem velhices, em formas que, mais além da localização etária "exata" no ciclo da vida, variam segundo as referidas características biológicas socialmente condicionadas, como o sexo/gênero, a raça/etnia e a própria posição social (BRITTO DA MOTTA, 2013, p. 16).

Antever a multiplicidade das experiências do envelhecimento possibilita apontar as diferentes práticas e possíveis demandas desse amplo grupo social. A interface com a condição de classe, por exemplo, pode determinar o estilo de vida, os limites de investimento no corpo e na saúde. As trajetórias sócio-históricas marcadas pelas disparidades de gênero também podem inferir no curso da velhice de homens e mulheres. Por isso, a categoria gênero é evocada neste estudo como ferramenta analítica capaz de fornecer um olhar sobre as relações sociais baseadas nas diferenças entre os sexos (SCOTT, 1995).

A construção da análise foi possível a partir da estratégia metodológica qualitativa, envolvendo a pesquisa de campo em uma Instituição de Longa Permanência e um grupo de convivência da "terceira idade", ambos localizados na cidade de Cuiabá (MT). A observação ocorreu entre os meses de março a julho de 2015 e neste período foram aplicadas oito entrevistas semiestruturadas em caráter de profundidade, gravadas e devidamente transcritas. Os/as informantes foram homens e mulheres com idade igual ou superior a 60 anos.

Na ILPI, as habilidades de fala, memorização e cognição dos/as residentes foram relevantes na seleção dos/as participantes da pesquisa. A escolha destes métodos de investigação permite um olhar apurado sobre as relações sociais e uma especial atenção aos elementos de crenças, atitudes, valores e motivações dos sujeitos em seus contextos sociais específicos (GASKEL, 2010).

O texto se divide em três partes: a primeira trata das representações sociais da velhice em diferentes períodos nas sociedades ocidentais e na atualidade; a segunda aborda o envelhecimento nas Instituições de Longa Permanência e a percepção que 
os/as velhos/as têm sobre seus corpos; e por último, analisa-se as representações sociais compartilhadas sobre o corpo velho a partir da ótica do envelhecimento saudável.

\section{As representações sociais da velhice nas sociedades modernas ocidentais}

A condição social dos/as velhos/as está intimamente ligada ao sentido historicamente impresso a sua existência. Ao revisitar as diferentes condições da velhice no percurso histórico das sociedades ocidentais, Beauvoir (1990) observa que as experiências do envelhecimento variam de acordo com o contexto social e cultural. Cada sociedade determina o lugar e o papel social dos/as velhos/as, ao mesmo tempo que o sujeito é orientado pela atitude prática e ideológica concebida pela sociedade.

Os estudos etnológicos consultados por Beauvoir (1990) revelavam como as sociedades "primitivas" classificadas como nômades e agrícolas aderiram ao sacrifício dos/as velhos/as. Outras sociedades marcadas por elementos da magia e feitiçaria permitiam aos/as integrantes longevos/as o acesso à posições sociais de destaque em virtude do duplo caráter de ameaça e admiração decorrentes dos poderes mágicos por eles/as adquiridos. Já nas sociedades consideradas mais avançadas, com técnicas mais elaboradas e dissociadas da magia, não se prezava pela influência dos/as mais velhos/as sobre a vida dos/as jovens. E por fim, nas sociedades industriais modernas, os/as velhos/as ocupavam lugar indefinido, sendo a velhice uma fase do ciclo vital tratada com desprezo, portanto, desprestígio social.

Na Idade Média, a condenação da velhice foi prática comum entre nobres e camponeses. A força física classificava posições sociais: "[...] os fracos não tinham lugar. A classe dos/as velhos/as não existia” (BEAUVOIR, 1990, p. 162). Para Ariès (200o), as sociedades cristãs medievais encaravam a velhice como um período de retiro. O homem velho recolhia-se aos estudos, às artes e à devoção; havia, por outro lado, a representação dos/as velhos/as enfermos/as e mal cheirosos/as provenientes das camadas sociais mais pobres.

$\mathrm{O}$ advento do capitalismo intensificou a exclusão dos/as velhos/as devido às mudanças nos valores e princípios referentes ao trabalho. Neste contexto, houve expressiva valorização da juventude em detrimento da velhice, pois a função de produzir rendimentos e contribuir economicamente destinava-se sobretudo aos homens jovens. O corpo se tornou instrumento essencial para o capitalismo. É através do corpo jovem, forte e ágil que se garante a produção e acumulação de capital, logo, os corpos envelhecidos, vistos muitas vezes como debilitados, contrariam valores centrais da modernidade, ou seja, a juventude, a vitalidade e o trabalho (LE BRETON, 2012).

As sociedades industriais ocasionaram a perda de status social dos/as velhos/ as. A industrialização teria gerado insegurança econômica e perda das relações 
estreitas que vigoravam nas sociedades tradicionais entre as gerações de uma mesma família (DEBERT, 2004).

Ariès (2000) sugere que o atual período histórico presencia uma maior desvalorização da velhice como consequência gerada pela produção de conhecimentos consumidos rapidamente, fenômeno resultante dos avanços científicos e tecnológicos. Os/as velhos/as não desfrutam de status em virtude da sabedoria por eles/as acumulada. Os conhecimentos apreendidos com a experiência de vida são vistos como antiquados diante da infinita produção de informações à disposição dos/as jovens.

Quando assimilado à decadência e ao isolamento, o envelhecimento impõe ao/a velho/a condição de "moribundo", termo utilizado por Elias (2001) para caracterizar os sujeitos "esquecidos" e marginalizados pela sociedade. A finitude da existência é um assunto de difícil abordagem nas sociedades ocidentais contemporâneas, logo, o medo da morte tende a afastar a figura do/a velho/a, reservando a ele/a os bastidores da vida social. Há uma recusa em aceitar a premissa da morte como destino comum para todos/as independentemente do investimento em cuidado e saúde.

Todas as sociedades produzem representações sociais, isto equivale a dizer que as concepções de mundo elaboradas, são a condição de existência e de preservação da memória social e das experiências dos sujeitos. A ação de avaliar e definir os seres e objetos, de compreender a realidade tal qual ela se apresenta, tornam familiar o não-familiar (MOSCOVICI, 2009).

Um arcabouço de símbolos e significados internalizados pelos sujeitos através das experiências e interações sociais, aciona o reconhecimento dos objetos, resgatando na memória os seus significados. O corpo velho tem sua imagem associada a um corpo frágil, adoecido e dependente de cuidados, o que corrobora para destituir os/as velhos/as de sua autonomia e controle de suas próprias decisões. Sobre esta questão, salienta Beauvoir (1990),

Mina-se a resistência do ancião, oprimindo-o com cuidados exagerados que o paralisam, tratando-o com uma benevolência irônica, falando-lhe em linguagem infantil. [...] Se a persuasão e a astúcia fracassam em fazê-lo ceder, não se hesita em mentir-lhe, ou em recorrer a um golpe de força. Por exemplo, convence-se o velho a entrar provisoriamente numa casa de aposentados, onde é abandonado. [...] impomos-lhes regras com relação ao vestuário, uma decência de maneiras, e um respeito às aparências (p. 268).

A figura do velho é representada de forma negativa, tendo em vista as limitações físicas, as faltas e ausências que a distanciam da concepção de sujeito enquanto dono de si mesmo (SORIA BATISTA; BANDEIRA, 2015). Essa ideia é também incorporada pelas avaliações médicas de desempenho nas Atividades 
da Vida Diária (AVD’s) e usadas para definir as condições funcionais e níveis de dependência dos/as velho/as.

As Atividades da Vida Diária são as tarefas de autocuidado que incluem alimentação, banho e higiene pessoal. Diante das debilidades para executar estas atividades básicas, a providência por cuidados especiais se torna indispensável. Em geral, este cuidado fica sob o encargo da família, exceto quando impossibilitada de assumir a responsabilidade.

Assim, as debilidades e a demanda por cuidado podem ser determinantes no destino dos/as velhos/as. Dentre as alternativas de cuidado formal, estão as Instituições de Longa Permanência para Idosos (ILPI's) - conhecidas também como "asilos" - as quais são designadas ao acolhimento e cuidado de velhos/as que não recebem amparo e apoio dos familiares e da comunidade.

A decisão pela institucionalização pode ser pessoal ou não, e implica ao/a velho/a o afastamento de suas antigas relações e a vivência em um ambiente institucional regido por regras e normas próprias. A admissão na instituição significa, muitas vezes, a ruptura definitiva dos antigos laços afetivos e a vida comunitária com pessoas desconhecidas (ELIAS, 2001, p. 85).

Beauvoir (1990) descreve estes estabelecimentos como verdadeiros depósitos de mendicância, frequentemente denunciados pelo poder público devido ao abandono médico, a insalubridade e a falta de estrutura adequada para acomodar os/ as residentes. Embora atualmente estas instituições estejam adquirindo um caráter mais burocrático, aderindo regulamentações, ainda assim estão associadas a essa imagem. Segundo Peixoto (2011), os asilos são herdeiros das antigas representações sociais: "lugares repugnantes, a mbientes mórbidos, abusos e a internação involuntária" (p. 346).

A historicidade das representações sociais sofre modificações ao longo do tempo. Os sentidos e os significados dos objetos de representação se transformam conforme o contexto sociocultural, a temporalidade e a dinâmica e interação com outros objetos de representação (MOSCOVICI, 2009).

A concretização de mudanças nas representações não abarca somente as instituições de acolhimento, mas também a própria ideia contida no processo de envelhecimento. Essas mudanças podem proceder do novo cenário sociodemográfico, que contabiliza o aumento do número de velhos/as e da expectativa de vida em vários países do mundo, incluindo o Brasil. Os/as velhos/as correspondem a uma parcela da população cada vez mais representativa e, portanto, ganha expressão e legitimidade no campo das preocupações sociais e do debate público (DEBERT, 2004).

Brito da Motta (2002) destaca que o momento de acelerada mudança coloca a imagem social do/a velho/a em transição. A autora afirma:

Na realidade, ainda coexistem as duas imagens: a tradicional, 'naturalizada', do inativo, respeitável, mas 'inútil'; e a nova imagem, mais dinâmica e participante, embora apenas em determinadas situações sociais (BRITO DA MOTTA, 2002, p. 48). 
Debert (2004) afirma que há um duplo movimento que acompanha essa preocupação social. Por um lado, a velhice foi considerada durante longo tempo como uma questão individual ou das associações filantrópicas e atualmente se transforma em questão de ordem pública. O campo da Gerontologia encarregado pela formação de especialistas do envelhecimento, aliado à tendência de homogeneização das representações da velhice, estabeleceram uma nova categoria cultural: "os idosos". A velhice foi caracterizada pela decadência física e ausência de papeis sociais, mas apesar das imagens negativas marcou a legitimação de direitos sociais, como a aposentadoria.

Por outro lado, a velhice é transformada em responsabilidade individual, o que Debert (2004) chama de "reprivatização da velhice" e, nesta lógica, ela poderia perder importância na agenda das preocupações sociais. Uma nova imagem do/a velho/a se constitui a partir da rejeição da velhice, enaltecendo a juventude como o padrão de vida que deve ser estendido as demais faixas etárias (LINS DE BARROS, 2011).

Permanecer jovem apesar da idade é sinônimo de bem-estar, saúde e qualidade de vida. E na aparição desta perspectiva da velhice, surge também um mercado de consumo voltado para esta nova categoria de consumidores denominada "terceira idade". A busca por "fórmulas" da juventude, métodos para prolongar o tempo de vida e atrasar as marcas naturais do tempo, fomenta um segmento econômico gradativamente expressivo.

Peixoto (2006) observa nos novos significados da experiência do envelhecimento, o aparecimento da categoria "terceira idade", que caracteriza a fase de transição entre a aposentadoria e a velhice. Para a autora, a "terceira idade" consiste em:

[...] produto da universalização dos sistemas de aposentadoria e do consequente surgimento de instituições e agentes especializados no tratamento da velhice, e que prescrevem a esse grupo etário maior vigilância alimentar e exercícios físicos, mas também necessidades culturais, sociais e psicológicas (PEIXOTO, 2006, p. 76).

Com efeito, a construção de novas concepções do envelhecimento fomenta o mercado de consumo empenhado em oferecer produtos e serviços aos/as novos/as consumidores/as. A velhice ativa e longeva exige do sujeito o investimento de tempo, dinheiro e disposição em cuidar do corpo com propósito de adequar-se a um estilo de vida saudável.

A oferta de receitas de técnicas de manutenção corporal, medicamentos e novas formas de lazer aparecem desestabilizando expectativas e imagens tradicionais ligadas a homens e mulheres mais velhos/as. A terceira idade surge como estágio apropriado para a concretização de sonhos adiados em outros momentos da vida 
(DEBERT, 2004), especialmente para as mulheres que estiveram dedicadas ao cuidado, ao trabalho doméstico e ao trabalho remunerado.

É importante salientar a maior rejeição das mulheres com relação ao processo de envelhecimento, dado o valor cultural atribuído ao corpo feminino. Do ponto de vista do gênero, as mulheres sofrem mais exigências com os padrões sociais pautados em um ideal estético que visa a juventude eterna. Favorecida pelo marketing e pela publicidade, a cultura do consumo apresenta fórmulas "milagrosas" para atender a produção dos corpos femininos, estes que representam um capital físico, simbólico, econômico e social (GOLDENBERG, 2009).

Neste sentido, a mídia e a publicidade operam na propagação dos ideais de estilo de vida, da responsabilização e "romantização" do envelhecimento. A produção e circulação das representações sociais são designadas pelo conjunto: cultura, linguagem, comunicação e sociedade. Os meios de comunicação de massa disseminam estas representações, contribuindo efetivamente para sua manutenção e transformação (SÁ, 1998). Assim, a difusão e circulação das representações ocorre mediante a produção e reprodução dos discursos sociais. É através dos discursos que se criam nós de estabilidade e recorrência, munindo as pessoas de um estoque de imagens e ideias socialmente aceitas e prontas para serem compartilhadas (MOSCOVICI, 2009).

\section{A velhice dos corpos institucionalizados}

Grande parte das Instituições de Longa Permanência (ILPIs) públicas e filantrópicas recebe velhos/as em situação de vulnerabilidade física, econômica e social. A marginalização e o isolamento resultam da destituição dos papeis sociais e de posições ocupadas na família e na comunidade de origem. A mudança para a instituição significa, muitas vezes, o confinamento e a ruptura dos vínculos afetivos e a adaptação pode ser traumática, sobretudo para as mulheres, cuja socialização esteve ligada à família e ao lar (BEAUVOIR, 1990).

A observação de campo revelou inúmeras debilidades físicas entre os/ as residentes da instituição, dentre elas, encontram-se algumas predominantes: problemas de visão, audição, comunicação e locomoção. As dificuldades se ampliam na realização de AVD's e atividades cognitivas, logo, a presença do/a cuidador/a é solicitada frequentemente. Muitas doenças adquiridas na senilidade podem progredir ao longo da permanência na instituição, levando ao agravamento do quadro de saúde. Além disso, medicamentos e tratamentos especializados são pouco disponibilizados pelas instituições, o que contribui sobremaneira para o avanço do grau de dependência dessas pessoas.

O cuidado dos corpos velhos institucionalizados é oferecido com vistas a atenuar processos de adoecimento em curso e já considerados críticos, na tentativa de propiciar assistência e algum conforto imediato ao sofrimento permanente. Mas 
vale mencionar que a dimensão mercadológica do cuidado que culminou no serviço oferecido nas ILPIs (GUIMARÃES, 2016), passou a exigir dessa atividade o rigor e a racionalização das técnicas instruídas pelos saber médico. A implementação de uma lógica Taylorista do trabalho do cuidado, pautada em princípios de eficiência laboral de produção, rendimentos e usos do tempo, condiciona uma produção em série e mecanizada. Portanto, a prioridade do cuidado, no contexto institucional, não está centrada na promoção da autonomia, em estratégias de prevenção de doenças ou na qualidade de vida dos/as residentes, mas na rotina de trabalho orientada pela economia de tempo e movimentos (BURILLE, 2018).

A ILPI na qual residem os/as informantes da pesquisa, é de natureza filantrópica e está localizada em uma região periférica da cidade. A estrutura predial antiga é composta por duas alas com quartos e salas que separam os/as "dependentes" e os/as "independentes"; e um grande pátio central lotado de bancos e cadeiras, circundado pelo refeitório, sala da direção, porta de entrada, entre outros cômodos. A maioria dos/as idosos/as acolhidos/as é oriunda de situação de vulnerabilidade social e necessita do cuidado integral não disponibilizado pelas famílias. Como forma de custear a moradia, os/as residentes contribuem com parte do valor das aposentadorias, porém a escassez de recursos básicos, medicamentos e o emprego de profissionais da saúde ficou evidente durante a observação de campo.

A pesquisa na ILPI revelou um perfil de idosos/as pretos/as e pardos/ as, entre 60 e 80 anos, solteiros/as, de religião católica, com ensino fundamental incompleto e que ao longo da vida exerceram atividades laborais precárias e de pouco reconhecimento, como o trabalho no campo (lavoura) assumido pelos homens, e o trabalho doméstico, exercido por mulheres. $\mathrm{O}$ tempo de permanência destes/as residentes na instituição contabiliza um período de um a três anos; todos/as possuem algum grau de deficiência ou doenças crônicas e degenerativas. A maioria dos/as moradores da instituição é composta por homens.

Ao serem questionados/as sobre a vivência na instituição, os/as entrevistados/ as $^{1}$ mencionaram a solidão, a dependência e o abandono como "sentimentos" presentes no cotidiano. É comum notar entre os/as residentes um olhar pouco otimista em relação à vida, e não raramente a vivência é acompanhada pelas mais variadas enfermidades.

O distanciamento familiar e a consequente fragilização dos vínculos afetivos são percebidos pelos/as idosos/as. O sentimento de abandono pelos/as filhos/as e a ausência de visitas são queixas recorrentes. M., morador da instituição, lamenta a displicência da filha e do genro há algumas semanas:

Olha, já tem quatro domingos que eles tão falando que vão vim me buscar, entendeu? Pra passar o domingo lá. Já vieram me buscar $a q u i$, né. Me prometeram que iam passar. Eu quero ir na casa

1 Como forma de preservar as identidades dos/as entrevistados/as, optou-se pela abreviação dos nomes. 
da minha irmã, que eu tenho uma irmã que mora lá no Terceiro (bairro da cidade), e depois descia e passava lá [...] (M., 8o anos)

C. menciona as raras visitas de seus familiares, mas encontra distração nas visitas de outros/as residentes:

As visitas que eu recebo, as visitas minhas são raríssimas. Mas eu gosto de conversar com as visitas dos outros. Eu fico "lalalalala" (conversando) e vou adquirindo mais conhecimento. [...] meu irmão nunca veio, e meu irmão mora aqui. Minha mãe já veio três vezes. Ela mora no Rio. Veio três vezes. Minha irmã também veio três vezes (C., 63 anos).

A representação social do/a velho/a poderia explicar a ausência das visitas dos familiares na instituição e o sentimento de abandono, pois para muito/as filhos/as pode ser difícil acompanhar o declínio da saúde física e mental dos pais. Segundo Elias (2001), a falta de empatia dos/as jovens com os/as velhos/as procede também do recalcamento envolvido nesta relação. O/a jovem, quando defronte ao/a velho/a em sua imagem depreciada, enxerga a si mesmo/a em um futuro condenado ao sofrimento, ao abandono e a morte, o que justificaria a rejeição e pouca solidariedade com a condição do/a outro/a.

[...] a identificação com os velhos e com os moribundos compreensivelmente coloca dificuldades especiais para as pessoas de outras faixas etárias. Consciente ou inconscientemente, elas resistem à ideia de seu próprio envelhecimento e morte tanto quanto possível. (ELIAS, 2001, p. 8o).

São muitas as circunstâncias que podem ocasionar a transferência dos/ as velhos/as para a instituição. A falta de recursos econômicos das famílias na providência de cuidados formais, conflitos geracionais, decisão voluntária, a ausência de um/a cuidador/a no domicílio, tempo disponível e o conhecimento das técnicas para o cuidado, podem motivar a decisão.

Ademais, a responsabilidade pelo cuidado está atrelada ao papel social das mulheres de acordo com a divisão sexual do trabalho estabelecida a partir das diferenças sexuais e das características socialmente construídas de homens e mulheres. $\mathrm{O}$ condicionamento apropriado ao trabalho do cuidado está associado a uma personalidade afetiva, emocional, maternal, atributos essencialmente femininos e naturalizados (MEAD, 1969).

Contudo, mudanças nas relações tradicionais de gênero e na estrutura familiar têm exigido novas estratégias de cuidado. $\mathrm{O}$ aumento da escolaridade das mulheres, a redução das taxas de fecundidade e a maior participação no mercado 
de trabalho não garantem mais uma disponibilidade das mulheres em tempo integral para o cuidado familiar (BITENCOURT, 2014; CAMARANO; KANSO, 2010). Além disso, historicamente as mulheres negras e das camadas mais desfavorecidas sempre assumiram postos de trabalho fora de casa, geralmente delegadas às tarefas domésticas de outras famílias (DAVIS, 2016). Estas mulheres enfrentam a ausência de cuidadores/as para seus/as entes vulneráveis, por vezes são as próprias cuidadoras formais ou informais, ou são aquelas usuárias das Instituições de Longa Permanência quando ficam mais velhas.

O caso de G. expressa essa realidade. Mulher negra de 60 anos, G. estudou até a sétima série e trabalhou como empregada doméstica até idade avançada. Após sofrer um derrame, precisou adaptar-se à cadeira de rodas e passou a depender de apoio para o banho e outras atividades. Sem filhos ou qualquer amparo familiar, mudou-se para a instituição, pois segundo ela, não havia alguém que pudesse auxiliála com tanta constância.

A dificuldade é por causa do derrame. Elas me levam no banheiro, a turma que trabalha aqui. [...] pra mim tenho medo de cair, bater aqui. No deitar eu fico com medo de cair. Morro de medo. Não sou capaz de deitar sozinha (G., 60 anos).

Na concepção de G., a referência de autocuidado se dá no âmbito da relação saúde/doença do corpo debilitado. Preocupa-se apenas em não agravar o quadro das deficiências e das perdas físicas que causariam maior dependência e sofrimento. A idosa pouco se interessa pelas atividades de entretenimento da instituição, mesmo os mais triviais, como assistir televisão, participar das atividades promovidas por voluntários/as ou interagir com visitantes e outros/as residentes.

Para Britto da Motta (1999, p. 210), dependendo da classe social e dos arranjos familiares, ser velho/a pode significar viver em situação de pobreza, com poucos recursos pessoais de sobrevivência. Envelhecer pode significar solidão, nos moldes de Norbert Elias (2001) ao tratar o isolamento dos "moribundos" no processo de decadência social e corpórea até o momento da morte. Pacheco (2008), ao analisar a solidão das mulheres negras de Salvador, compreende que o sentido de ficar só não se traduz unicamente pela "escolha" total do sujeito, indicando que aspectos sociais e culturais são importantes para pensar as experiências objetivas e subjetivas destas mulheres.

Sobre as razões que levaram à mudança para a ILPI, o entrevistado M. responde:

Eu vim morar aqui por causa das minhas filhas, porque nenhuma casa delas tem condição de me dar um certo conforto. Se eu for ficar lá na casa da minha filha eu vou ficar sozinho, sozinho. Ela põe tudo quanto é comida, água, ali, e vai para o trabalho. Sai de manhã cedo e só chega de noite. Eu fico ali sozinho, entendeu? Eu vou tomar banho quando ela chega. E é um trabalho danado. 
Quando eu andava, mesmo de muleta, sozinho, era mais fácil né, eu ia no banheiro (M. 8o anos).

O cuidado envolve tempo, trabalho e uma assistência que muitas vezes requer técnicas específicas, conhecimentos especializados, provoca desgaste físico e emocional, causando sobrecarga de trabalho às mulheres que assumem a responsabilidade. No caso do entrevistado M., há, ainda, outro agravante. O grau de dependência impede a sua locomoção, por isso, precisou se adaptar ao uso da cadeira de rodas, prejudicando a mobilidade dentro da casa da filha. Destarte, as Instituições de Longa Permanência têm sido para muitas famílias uma alternativa de cuidado dos/as velho/as.

Durante as visitas na instituição e conversas informais, poucos momentos de socialização entre os/as residentes foram presenciados. Foi identificada certa resistência para a aproximação, diálogos ou amizades. Perguntados/as sobre essa questão, alguns/umas se referem aos/as outros/as como "loucos/as" e "velhos/ as demais" para uma amizade. Para eles/as, as doenças crônicas e degenerativas criam barreiras para a socialização e para estabelecer novos laços afetivos, pois não despertam confiança. A demência, o Alzheimer e outros transtornos mentais reduzem as chances de construir relações.

A condição de dependência seguida da perda das capacidades cognitivas aflige o imaginário dos/as velhos/as, principalmente aqueles mais debilitados/ as que vivenciam o agravamento das doenças e necessitam do apoio na realização das Atividades da Vida Diária. Na visão dos/as residentes, a dependência equivale a condição de sujeição, tanto em relação aos/as cuidadores/as, como também à equipe dirigente da instituição. Os sentimentos de desconfiança e ameaça são comuns. Para os/as residentes, o ambiente institucional exige dispor de lucidez e capacidades cognitivas capazes de assegurar certa autonomia nas decisões.

Algumas doenças marcam o aspecto físico dos corpos e impõem limitações nas atividades corriqueiras. Alguns relatos acusam as doenças crônicas e degenerativas de prejudicarem a saúde, o bem-estar e o convívio social. Em sua fala, M. elenca alguns problemas que afetam sua rotina e, consequentemente, a autonomia:

O primeiro problema é esse aqui da hérnia, né. Segundo, é uma coceira que eu tenho no meu braço, olha como que tá, isso me irrita, me deixa eu... a noite então, pra eu dormir é aquela coisa, incomoda. E no fim eu sinto vários problemas que estão me incomodando, viu. Problema da vista. A vista eu enxergo, só que não dá pra mim ler. E outra coisa que eu fico triste é que eu não sei mais nem assinar meu nome. Eu pego a caneta para assinar meu nome, e não tem nem estabilidade. (M., 80 anos).

A relação dos/as velhos/as com a dependência funcional é marcada pelos esforços para agir no mundo, pelas dificuldades de manipular o próprio corpo, ter 
controle sobre suas reações orgânicas. A dor é companheira diária, está presente nos movimentos simples, se torna natural e inerente ao sujeito (BURILLE, 2018).

O entrevistado S. revela a decisão pessoal de mudança para a ILPI. Para ele, residir na instituição significa a garantia de cuidados em período integral realizado pela equipe de cuidadores/as sempre que necessário. Antes da mudança para a instituição, S. residia sozinho e dependia da disponibilidade de ajuda dos/ as vizinhos/as e amigos/as. Na entrevista, S. detalha os problemas de saúde e os cuidados recebidos na ILPI:

Aqui é tranquilo. A pessoa adoece e tem qualquer problema, aí tem quem cuida. Graças a Deus to tomando remédio e to bem. Melhorei. Eu me trato aí no hospital Julio Muller tem 16 anos. Então mês que vem também tenho consulta pra fazer [...]. eu já fiz exame de todo tipo. [...] agora acabou, mas eu tive muito ruim. Eu operei da hemorroida faz uns três anos e pouco. Eu só tenho essa vista (aponta para o olho direito), a outra eu perdi. Operei dessa das cataratas. Bem bom, graças a Deus, enxergo bem, tudo. [...] Primeiro tratamento que eu fiz aí foi de leishmaniose. Se eu não cuido já tinha perdido o nariz. Aí então faz tempo que eu consultei. Mas graças a Deus tá tudo bem. Aí a outra é do coração, que o doutor marcou. Aí ele passou dois tipos de remédios pro colesterol, aí eu tomo todo dia. Aí depois que to aqui eu tive uma tremedeira nesse braço. Pegava as coisas assim e tava tremendo. Uma dor na perna. A face de Deus é o doutor, né. Aí eu fui lá consultar com esse doutor do coração e falei que tava sentindo isso [...], aí ele me passou um comprimido que eu tomo quatro por dia. [...] mas to tomando o remédio e posso ficar em pé, posso ficar sentado... (S., 72 anos).

Se, para os jovens, algumas atividades são realizadas com destreza e agilidade, para os/as velhos/as podem ser exaustivas e até impraticáveis a depender do estágio das doenças enfrentadas. A deficiência cria obstáculos para o corpo que, no mundo do trabalho, passa a ser marginalizado, assistido pela seguridade social, sob o risco de ser afastado da vida coletiva (LE BRETON, 2007).

Caradec (2011, p. 25) analisa a maneira como as manifestações corporais contribuem para o advento do sentimento de envelhecer e aponta três registros indicadores das preocupações dos/as velhos/as em matéria de saúde, beleza e forma: o registro do "corpo orgânico", da aparência e da energia. O registro do corpo orgânico diz respeito à saúde e às capacidades físicas, estas que podem variar: por um lado, as aptidões físicas conservadas e a ausência de doenças, e por outro, a debilidade dessas capacidades e as limitações funcionais e doenças oriundas do processo de envelhecimento. $\mathrm{O}$ registro da aparência consiste nas dimensões plásticas do corpo, a exemplo das rugas e da despigmentação dos cabelos. A preocupação nesse sentido é de ordem estética e não mais referente à saúde. E por último, o registro da energia 
concerne à vitalidade do corpo, a sensação de "estar em forma" e o sentimento de bem-estar, opostos à sensação de fadiga e fraqueza.

A análise de Caradec (2011) aplicada ao contexto institucional para a compreensão do sentimento de envelhecer demonstra, a partir das falas dos/ as residentes, que os registros do corpo, da aparência e da energia manifestamse de modo negativo. Para este grupo, o envelhecimento não traduz sentimentos de satisfação ou otimismo. Se, para muitos/as velhos/as, a "terceira idade" pode significar o desfrute de tempo, liberdade e prazeres proporcionados pelo mercado de consumo, para os/as institucionalizados/as, a velhice ainda é sinônimo de dissabor e resignação.

A entrevistada C., moradora da instituição, recorda o cuidado dedicado à aparência física nos tempos da juventude e o corpo como alvo da atenção masculina:

Eu fazia academia. Eu procurava ter meu corpo bem, bem, bem ajeitadinho. Eu era muito bonita, sabe. Os homens todos, quando eu passava... eu ficava feliz de os homens mexerem comigo. $O$ cabelo bem comprido, assim. [...] fazia corridas na universidade. E eu toda semana eu controlava meu peso, alimentação... (C., 63 anos).

Quando questionada sobre a percepção em relação ao corpo em processo de envelhecimento, C. admite:

C.: eu me sinto... uma velha.

Entrevistadora: e o que é ser velha pra você?

C.: o que é ser velha pra mim? É ser descuidada.

O sentido da palavra "velha" está associado à falta do cuidado de si. Nos termos de Foucault (2005), o autocuidado, as normas e recomendações ditadas pelo saber médico foram incorporados nas práticas e condutas cotidianas dos sujeitos, na atenção e vigilância com a saúde, alimentação e exercícios físicos.

Para a entrevistada, "ser velha" exprime o efeito subjetivo de perda do valor social do corpo. Segundo Goldenberg (2009), o estigma depositado na condição da velhice retira da mulher as suas qualidades de beleza e atratividade, tornando-a invisível perante o olhar masculino. O prestígio do corpo é um elemento demasiado relevante na cultura brasileira e incide fortemente sobre as mulheres, estas constantemente incentivadas a conservarem a juventude e a beleza de seus corpos (GOLDENBERG, 2005). Especialistas em saúde e manuais de autoajuda estão empenhados em convencer as pessoas de que as imperfeições do corpo não são naturais, basta o esforço e trabalho corporal disciplinado para manter ou conquistar a aparência desejada. Os cosméticos, a ginástica, as vitaminas e a indústria do lazer (DEBERT, 2004) proporcionam uma ampla gama de diferentes produtos e serviços, 
cuja finalidade comum é conservar a juventude e convencer sobre os benefícios da longevidade.

Frente ao fracasso da busca incessante pela eterna juventude, está implícita a suposta falta de esforço ou dedicação suficientes para o combate da velhice. Mesmo quando as fórmulas da longevidade são inacessíveis em virtude das condições socioeconômicas, a responsabilidade pela decadência do corpo é individualizada. Para Simões (2000), os/as velhos/as carentes e dependentes são culpados pela sua condição porque não adotaram técnicas de manutenção corporal e rejuvenescimento. No contexto institucional, o olhar que os/as velhos/as têm de si, corresponde, em certa medida, a essa responsabilidade não atendida da autovigilância, por isso a noção de que estão condenado/as à deterioração de seus corpos e culpados pelo próprio sofrimento.

\section{A longevidade saudável e os corpos ativos}

Nas últimas décadas, surgiram no Brasil inúmeros espaços voltados para pessoas idosas, citando como exemplos as "escolas abertas", "universidades para a terceira idade” e grupos de convivência. Esses programas encorajam pessoas com idade igual ou superior a 60 anos a viverem coletivamente a experiência do envelhecimento (DEBERT, 2004, p. 15).

O grupo de convivência que foi locus da pesquisa, segue esse propósito oferecendo aulas de hidroginástica, musculação, treinamento funcional, tai geiko, aulas de canto coral, cursos de informática e de idiomas à baixo custo para funcionários/as aposentados/as da Universidade e da comunidade ampla. O projeto é uma iniciativa da Universidade Federal de Mato Grosso (UFMT) e foi criado com objetivo de incentivar a prática de exercícios físicos que melhoram o equilíbrio do corpo, a força física, a agilidade motora e a postura, além de incentivar a integração entre os/as participantes.

$\mathrm{O}$ perfil dos/as participantes do grupo corresponde à idade entre 60 e 80 anos, pretos/as e pardos/as, de religião católica, casados/as e divorciados/as, com ensino médio completo. Ao longo de suas trajetórias de vida, estiveram inseridos/ as em atividades da construção civil, serviços de garçom (homens), e serviço público e de secretariado (mulheres). Atualmente são aposentados/as, mas alguns/as permanecem exercendo alguma atividade remunerada. Estes/as idosos/as, em geral, residem em bairros afastados da Universidade e utilizam transporte público como meio de deslocamento.

A promessa da promoção de "qualidade de vida" encoraja a adesão ao programa. Muitos/as integrantes participam de outras organizações além desta, como por exemplo, grupos de dança, de artesanato, eventos religiosos e grupos de excursões. Segundo Peixoto (2006), a oferta dessa categoria de serviços tem despertado o interesse de pessoas velhas, sendo encarada como alternativa para 
prorrogar os sinais da velhice. Produtos de beleza, pacotes de turismo, alimentos, medicamentos e especialistas gerontólogos/as e geriatras estão acessíveis no amplo mercado de consumo, dispostos a atender um número crescente de consumidores.

A maioria dos participantes desse grupo de convivência é constituída por mulheres, confirmando a tese de Debert (2013) sobre a discreta participação masculina nos programas dessa natureza. Essas participantes buscam conservar a aparência física e evitar a manifestação de doenças crônicas e degenerativas adversas, como por exemplo, doenças cardiovasculares, artrite e doenças que afetam as capacidades cognitivas, tais como doença de Alzheimer e demência. A perda de autonomia é, para elas, o maior risco ocasionado na velhice. Em entrevista, a participante $H$. relata os desconfortos físicos provocados pelas doenças e que são remediados pelos exercícios praticados no grupo:

Às vezes você tem algum probleminha de dor. Agora mesmo tá aparecendo. Vai aparecendo artrose, essas coisas assim. Mas pelo fato quando... Porque eu faço musculação e faço hidro, né. Mas a musculação e a hidro ajudam bastante. [...] agora ultimamente que tá aparecendo as dores, assim, artrose, né. Mas é por que? Porque lá em casa tem escada, entendeu? Então não tem jeito de você sair fora. Quinze degraus. Sobe e desce. Então é isso que ajuda. Mas não chega a ser tanto por causa do exercício físico que eu faço. [...] e com a idade, o tempo vai passando, aí vai aparecendo, lógico,

O predomínio de mulheres nos espaços que competem ao cuidado do corpo indica maior atenção e dedicação de tempo voltados para a saúde e a aparência física. A cobrança social sobre os corpos femininos acarreta a maior procura por programas semelhantes a este, cuja finalidade é prevenir o envelhecimento e suas consequências à saúde e ao bem-estar.

Os sinais corporais denunciam o envelhecimento e revelam a distinção entre a juventude e velhice: a pele enrugada, cabelos grisalhos, os movimentos lentos e as dificuldades na mobilidade são indicadores da idade avançada. Na interação entre o sujeito velho e a sociedade, estes sinais são interpretados e operam como marcadores simbólicos. A entrevistada H. descreve sua experiência ao usufruir o direito à passagem gratuita concedida às pessoas acima de 60 anos que necessitam do sistema de transporte público:

Porque o cabelo branco você chega no ônibus, a pessoa logo já fica te cuidando, assim, entendeu? Então, não preciso... eu pego o ônibus e já vou lá atrás, não preciso ficar mostrando carteira 
mais... mostrar a carteirinha de idoso, porque seu cabelo já tá mostrando a sua idade. Então eu vou ficar trazendo carteirinha?! Não levo mais. Eu só dou o sinal pra ele, 'ó, lá atrás!'. Ele já abre a porta. (H., 63 anos)

Os marcadores simbólicos da idade avançada são elaborados em todas as sociedades pelos indivíduos, estabelecendo um sentido político e organizador do sistema social (MINAYO, 2011). Certos elementos exteriores, tais como políticas sociais e políticas de saúde, evocam a idade cronológica advertindo constantemente a posição socialmente ocupada pelos/as velhos/as (CARADEC, 2011). Nesse sentido, as instituições sociais padronizam e regulam comportamentos, gostos, maneiras e sentimentos de ser velho/a. Na perspectiva durkheimiana (1989) a consciência coletiva interfere nas consciências individuais, logo, o sentimento de envelhecer é absorvido de "fora" para "dentro". Do mesmo modo, as representações sociais do envelhecimento são produzidas e reproduzidas pelas instituições e exteriores aos indivíduos, penetram nas mentes e conduzem determinados comportamentos.

As mudanças fisiológicas no corpo também interferem na relação com o trabalho e a produtividade, principalmente para os homens. Tanto os homens residentes da instituição quanto os participantes do grupo de convivência afirmam que no decorrer do envelhecimento houve redução no rendimento do trabalho. $\mathrm{O}$ abandono das atividades profissionais e a aposentadoria são de difícil adaptação para os homens velhos.

A experiência masculina no processo de envelhecimento está vinculada à perda das habilidades exercidas no trabalho. As falas dos entrevistados (do residente da ILPI e do participante do grupo de convivência, respectivamente) manifestam sentimentos de inutilidade e impotência frente à situação de dependência funcional:

E lá fora quando eu trabalhava eu escrevia 30, 40 talões do consumidor pro freguês. Hoje não sou capaz de assinar meu nome. Isso pra mim é minha maior tristeza. Mas enquanto isso tudo bem, porque eu não vou mais trabalhar mais na loja onde eu trabalhei, minha profissão, que ninguém vai me aceitar mais com 8 o anos desse jeito, ninguém vai... firma nenhuma não aceita (M., 80 anos).

Isso aí é até no serviço que você faz. Serviço que a gente fazia aí por meio dia, hoje você passa quase o dia inteiro, né. [...] o piso mesmo eu gosto de fazer, o azulejo, esses negócios aí quase não cansa a gente, né. Mais tranquilo. Agora, a gente sente sim, porque você não sobe mais o andaime, eu trabalhava naquele Jaú Balancim que é por fora, balançando, assim, pra fazer massa, né. Hoje eu não faço mais isso porque né, pode cair, e a gente tem aquele medo [...] (J., 76 anos) 
Como afirma Ecléa Bosi (1994), “a sociedade rejeita o velho" e ao perder a força de trabalho, não se faz produtor nem reprodutor. Essa condição representa sacrifício para os homens, pois ao longo da vida social tiveram um contato mais direto com a esfera pública e com as relações de trabalho. Deste modo, para alguns homens a velhice representa um período de reclusão e tristeza. Muitos encaram este estágio com dificuldades, pois suas identidades de gênero foram construídas com base na trajetória de vida no trabalho, meio de inserção dos sujeitos no sistema de relações econômicas e sociais. A velhice masculina é vivenciada de diferentes formas dependendo do local estratégico ocupado pelo homem na hierarquia masculina (MENDES, 2002).

Na visão dos/as idosos/as do grupo de convivência, o envelhecimento saudável proporciona bons resultados no desempenho das atividades do cotidiano, inclusive em atividades profissionais que porventura ainda exercem, e até mesmo na construção de relações sociais e na preservação da saúde mental. Para as mulheres, o grupo é um lugar de descontração, onde é possível socializar e praticar exercícios, hábitos até então impossíveis de serem inseridos na rotina em virtude dos compromissos com o trabalho e o cuidado doméstico. A entrevistada H. relata:

[...] não dava tempo porque tinha as crianças pequenas, as coisas de casa. Eu trabalhava as vezes na parte da manhã, as vezes eu fazia curso a noite e assim não dava tempo, tinha que dar o mamá pra criança. Que eu falo, a gente dá de mamar pra todo filho. (H., 63 anos).

Essas mulheres se veem, agora, "livres" das obrigações e controles reprodutivos e prontas para aproveitarem, finalmente, as benesses da vida. Britto da Motta (1999) percebe uma "dupla valência" no sentido de "liberdade" para essas mulheres. Por um lado, podem viver conforme sua vontade, porém, essa vivência é marginalizada, uma vez que já não são bonitas - segundo os parâmetros estéticos - não reproduzem e não despertam a atração masculina.

É importante mencionar a vigilância de familiares e médicos/as, estes que incentivam a participação destes/as idosos/as no grupo de convivência. Em geral, médicos/as e especialistas recomendam a prática de esportes, mudanças de hábitos, escolha de um estilo de vida saudável como meio para permanecerem ativos/as e integrados/as socialmente. Britto da Motta (2002) argumenta que:

Os corpos são cada vez mais, loteados pelas especialidades médicas e afins, segundo aparelhos e sistemas fisiológicos... $\mathrm{E}$ idades. O corpo dos velhos é o corpo "diferente", comparado - em desvantagem - como o modelo de corpo e beleza jovens vigente na sociedade, manipulável para se aproximar deste. Uma série de profissionais cuida desse aspecto: "alimentação saudável", exercícios físicos, ainda mais eficazes se realizados "sob orientação 
especializada" em academias ou com um personal trainer, dança de salão, moda mais jovem, etc. (BRITTO DA MOTTA, 2002, p. 43).

A medicina enquanto porta-voz do conhecimento científico condiciona o cuidado dos corpos através de saberes estabelecidos e consolidados. Os corpos vulneráveis são mais facilmente conduzidos por preceitos do saber médico. Afinal, a ciência é também formuladora de representações sociais.

\section{Considerações finais}

As representações do corpo envelhecido são construídas tendo como referência a dimensão simbólica das representações sociais do corpo jovem. O ideal de envelhecimento se constrói a partir destas representações imbuídas dos discursos que legitimam a responsabilidade do indivíduo no cuidado do corpo, na manutenção da saúde e que inferem um envelhecimento "adequado". Nessa perspectiva, as desigualdades oriundas das estruturas sociais são mascaradas e naturalizadas, o que convém, nesse sentido, para negligenciar o papel social do Estado na promoção de políticas públicas destinadas à população velha.

Nessa pesquisa, foi possível evidenciar as diferenças que marcam as concepções de homens e mulheres sobre o processo de envelhecimento e do significado de um envelhecimento bem-sucedido ou fadado ao fracasso. A perda do valor social nesta etapa da vida é intensificada quando diante da condição de dependência, da falta de autonomia para realizar Atividades da Vida Diária ou produzir trabalho. Os corpos enquanto construções sociais, são marcados pelo gênero, raça e classe social, estão localizados no tempo e espaço sociais, e portanto, vivenciam distintamente a experiência da velhice.

A imagem do/a velho/a associada à figura do "moribundo" estimula a preocupação em retardar este processo. Os/as participantes do grupo de convivência demonstraram maior preocupação com a prevenção de doenças e são adeptos/ as ao discurso da qualidade de vida transmitido pelos/as especialistas médicos/ as. Estes velhos e velhas encontram sentido na convivência social e desfrutam o que julgam como "benefícios da terceira idade". As redes de apoio familiares, as condições econômicas e as trajetórias de vida marcadas pelo trabalho e independência financeira das mulheres, podem ter contribuído significativamente para a busca de um envelhecimento saudável e uma concepção de velhice ativa e longeva. Contrariamente, os/as idosos/as da ILPI demonstraram indisposição para a interação social ou qualquer iniciativa para um envelhecimento ativo. A falta de recursos e incentivos por parte da instituição e de seus gestores, evidenciou certa "naturalização" deste ambiente como o lugar da "solidão dos moribundos". A velhice, 
para estes/as residentes, é a etapa final da existência, preenchida pela dor, sofrimento e dependência.

Para as mulheres, a velhice representa um processo ainda mais conturbado em razão da cobrança social incisiva na produção de corpos femininos ideais. Os padrões de beleza e as representações sociais do corpo jovem estimulam a rejeição do corpo velho. Já os homens compartilham as angústias relativas ao distanciamento do trabalho.

As representações sociais tradicionais do envelhecimento caracterizadas pela reclusão, isolamento, inatividade e "morte" social já destoam da realidade vivenciada por muitos/as velhos/as. Por outro lado, as novas representações construídas em torno do envelhecimento transferem para o domínio privado a responsabilidade pelo autocuidado e pelo cuidado dos/as entes velhos/as, e se mostram limitadas para lidar com as demandas da idade avançada.

É urgente um conjunto de esforços formado pelas diversas áreas do conhecimento para a produção de estudos e pesquisas sobre o envelhecimento, bem como o interesse dos segmentos políticos e sociais para a incorporação deste tema no debate público. As considerações apontadas neste estudo confirmam a importância do reconhecimento das representações sociais como norteadoras na formulação de estratégias políticas e sociais que propõem a integração das diversas velhices na sociedade ampla.

\section{Referências Bibliográficas}

ARIÈS, Philippe. ¿Una historia de la vejez? Entrevista com Philippe Ariès. Archipiélago: Cuadernos de crítica de la cultura, n. 44, 2000, p. 50-61.

SORIA BATISTA, Analía \& BANDEIRA, Lourdes Maria. Trabalho de cuidado: um conceito situacional e multidimensional. Revista Brasileira de Ciência Política, n. 18, 2015, p. 59-8o.

BEAUVOIR, Simone de. A velhice. Rio de Janeiro: Nova Fronteira, 1990.

BITENCOURT, Silvana Maria. Quando o corpo não é mais aquele: definindo o envelhecimento a partir dos "moribundos" asilados. In: Anais do VIII Congresso Português de Sociologia. Évora: 40 anos de democracia(s): progressos, contradições e prospectivas: APS, 2014, p. 380-390.

BOSI, Ecléa. Memória e sociedade: lembranças de velhos. São Paulo: Companhia das letras, 1994. 
BRITTO DA MOTTA, Alda. Envelhecimentoesentimento docorpo. In: MINAYO, Maria Cecília \& COIMBRA JUNIOR, Carlos (orgs.). Antropologia, saúde e envelhecimento. Rio de Janeiro: Editora FIOCRUZ, 2002, p. 37-50.

BRITTO DA MOTTA, Alda. As idades da mulher. Revista Feminismos, v. 1, n. 3, set./ dez., 2013.

As dimensões de gênero e classe social na análise do envelhecimento. Cadernos Pagu, n. 13, 1999, p. 191-221.

BURILLE, Stephanie Natalie. Instituições de Longa Permanência e o cuidado de pessoas idosas em situação de dependência funcional. Dissertação (Mestrado em Sociologia). Brasília: Universidade de Brasília, 2018.

CAMARANO, Ana Amélia \& KANSO, Solange. Como as famílias brasileiras estão lidando com idosos que demandam cuidados e quais as perspectivas futuras? A visão mostrada pelas PNADs. In: CAMARANO, Ana Amélia (org.). Cuidados de longa duração para a população idosa: um novo risco social a ser assumido? Rio de Janeiro: IPEA, 2010.

CARADEC, Vincent. Sexagenários e octagenários diante do envelhecimento do corpo. In: GOLDENBERG, Mirian (Org.). Corpo, envelhecimento e felicidade. Rio de Janeiro: Civilização Brasileira, 2011, p. 21-44.

CITELI, MariaTeresa. Fazendodiferenças:teoriassobregênero, corpoecomportamento. Revista Estudos Feministas, Florianópolis, vol. 9, n. 1 2001, p. 131-145.

DAVIS, Angela. Mulheres, Classe e Raça. São Paulo: Boitempo, 2016.

DEBERT, Guita Grin. A reinvenção da velhice: socialização e processos de reprivatização do envelhecimento. São Paulo: EDUSP, 2004.

. Feminismo e velhice. Revista Sinais Sociais, Rio de Janeiro, vol. 8, n. 22, 2013, p. 1-152.

DURKHEIM, Émile. As formas elementares da vida religiosa: o sistema totêmico na Austrália. São Paulo: Paulinas, 1989.

ELIAS, Nobert. A solidão dos Moribundos, seguindo de envelhecer e morrer. Rio de Janeiro: Zahar, 2001. 
FERNANDES, Maria das Graças Melo; GARCIA, Loreley Gomes. O corpo envelhecido: percepção e vivência de mulheres idosas. Interface - Comunic., Saúde, Educ., Botucatu, 2010, p. 401-412.

FOUCAULT, Michel. História da Sexualidade III: O cuidado de si. São Paulo: Graal, 2005 .

GASKELL, George. Entrevistas Individuais e Grupais. In: BAUER Martin \& GASKELL George (orgs.). Pesquisa qualitativa com texto, imagem e som: um manual prático. Petrópolis, RJ: Vozes, 2010, p. 65-89.

GUIMARÃES, Nadya A. Casa e Mercado, amor e trabalho, natureza e profissão: controvérsias sobre o processo de mercantilização do trabalho de cuidado. Cadernos Pagu, n. 46, jan./abr., 2016. p. 59-77.

GOELLNER, Silvana Vilodre. A produção cultural do corpo. In: LOURO, Guacira. L.; FELIPE, Jane. \& GOELLNER, Silvana V. (orgs.). Corpo, gênero e sexualidade: um debate contemporâneo na educação. Petrópolis: Vozes, 2012.

GOLDENBERG, Mirian. Estudos sobre gênero, sexualidade e moda na cultura brasileira. São Paulo: Estação das letras e cores, 2010.

. Coroas: corpo, envelhecimento, casamento e infidelidade. Rio de Janeiro:

Record, 2009.

GUERRA, Juliana de Farias Pessoa. Subjetivações femininas na meia-idade: a vivência da menopausa na contemporaneidade. 2017. Tese (Doutorado em Sociologia). Recife: Universidade Federal de Pernambuco, 2017.

JAPIASSU, Hilton. O mito da neutralidade científica. Rio de Janeiro: Editora Imago, 1981.

LE BRETON, David. Sociologia do Corpo. Petrópolis: Vozes, 2007.

Antropologia do corpo e modernidade. Petrópolis: Vozes, 2012.

LINS DE BARROS, Myriam Moraes. A velhice na pesquisa socioantropológica brasileira. In: GOLDENBERG, Mirian (Org.). Corpo, envelhecimento e felicidade. Rio de Janeiro: Civilização Brasileira, 2011, p. 45-64.

MARTIN, Emily. O óvulo e o espermatozoide: como a ciência construiu um romance baseado em papeis estereotipados masculinos e femininos. In: LASLET, Borg (org.). Gender and scientific autority. Chicago: University of Chicago, 1996. 
MARTIN, Emily. A mulher no corpo: uma análise cultural da reprodução. Rio de Janeiro: Editora Garamond, 2006.

MEAD, Margaret. Sexo e temperamento. São Paulo: Perspectiva, 1969.

MENDES, Juliana Cavilha. Histórias de Quartel: um estudo de masculinidades com oficiais fora da ativa Dissertação (Mestrado em Antropologia). Florianópolis: Universidade Federal de Santa Catarina, 2002.

MINAYO, Maria Cecília de Souza. Envelhecimento demográfico e lugar do idoso no ciclo de vida brasileira. In: TRENCH, Belkis.; ROSA, Tereza E. C. (orgs.). Nós e o outro: envelhecimento, reflexões, práticas e pesquisa. São Paulo: Instituto de Saúde, 2011.

MOSCOVICI, Serge. Representações sociais: investigações em psicologia social. Petrópolis: Ed. Vozes, 2009.

PACHECO, Ana Cláudia Lemos. "Brancas para casar, mulata para f..., negra para trabalhar": Escolhas afetivas e significados da solidão entre mulheres negras em Salvador, Bahia. 2008. Tese (Doutorado em Ciências Sociais). Campinas: Universidade Estadual de Campinas, 2008.

PEIXOTO, Clarice Ehlers. Sobre a institucionalização da velhice e as condições de asilamento. In: GOLDENBERG, Mirian. (org.) Corpo, envelhecimento e felicidade. Rio de Janeiro: Civilização Brasileira, 2011, p. 341-356.

Entre o estigma e a compaixão e os termos classificatórios: velho, velhote, idoso, terceira idade. In: LINS DE BARROS, Myriam. (org.). Velhice ou terceira idade? Estudos antropológicos sobre identidade, memória e política. Rio de Janeiro: Editora FGV, 2006, p. 69-84.

SÁ, Celso Pereira. de. A construção do objeto de Pesquisa em Representações Sociais. Rio de Janeiro: EDUERJ, 1998.

SCOTT, Joan. Gênero: uma categoria útil de análise histórica. Educação \& Realidade. Porto Alegre, v. 20, n. 2, jul./dez., 1995, p. 71-99.

SIMÕES, Júlio Assis. Entre o lobby e as ruas: movimento de aposentados e politização da aposentadoria. Tese (Doutorado em Antropologia) Campinas: Universidade Estadual de Campinas, 2000.

Recebido em 25/11/2020.

Aceito em 07/06/2021. 